\title{
The Role of Shame in Women's Recovery from Alcoholism
}

\author{
Shelly A. Wiechelt, Ph.D. \\ Ph.D., University of Pittsburgh, 1999 \\ Assistant Professor \\ State University of New York at Buffalo
}

\section{Statement of the Research Problem}

Historically, society has viewed alcoholism as a male problem. Consequently, alcoholism research has focused on the experience of alcoholic males and considered women as a special case. The findings from research conducted on males have often been applied to women without research on women to substantiate such application (Klee, Schmidt, \& Ames, 1991; Wilke, 1994). Even though research on alcoholism in women has increased over the past twenty years, knowledge about women still pales in comparison to the knowledge that has been developed on male alcoholics.

Currently, it is estimated that 4.1 million women can be classified as alcoholic or problem drinkers (NIAAA, 1993). The ratio of male to female alcoholics has been estimated between 1:1 and 7:1 (Abbott, 1995). Clearly, women suffer from the effects of alcoholism, yet there is limited research on their addiction and recovery processes. Additional research is needed to enhance our understanding of alcoholism in women and thereby improve their treatment.

Childhood sexual abuse has been identified as a factor that contributes to the development of alcoholism in women and seems to inhibit their recovery. Research has shown that $34 \%$ to $77 \%$ of alcoholic women have been sexually abused in childhood (Covington, 1982; Covington \& Kohen, 1984; Hurley, 1991; Kovach, 1986; Miller \& Downs, 1993; Miller, Downs, Gondoli, \& Keil, 1987; Rosenhow et al., 1988). Existing treatment strategies do not sufficiently address the complex treatment needs of alcoholic women who have experienced childhood sexual abuse. In order to develop more sophisticated treatment strategies that will improve the recovery process for alcoholic women, a better understanding of the links between childhood sexual abuse and the difficulty that women experience in recovery is needed. One possible link is internalized shame.

Shame has been identified as an effect of childhood sexual abuse and a problem for alcoholic women throughout the literature (Briere \& Runtz, 1993; Feiring, Taska, \& Lewis, 1996; Gomberg, 1988; Hall, 1996; Nathanson, 1989; Playter, 1990; Skorina \& Kovach, 1986). Most alcoholic women describe an experience of shame when they begin recovery. Their experience of shame abates as they progress in the recovery process (Playter, 1990; Ramsey, 1988). For women who are recovering 
from alcoholism and experienced childhood sexual abuse, shame does not seem to abate and may even intensify. Without the anesthetizing effects of alcohol and the distraction of active addiction, memories and intense shame associated with childhood sexual abuse emerge. The intense shame can be overwhelming and makes recovery from alcoholism difficult for women who are survivors of childhood sexual abuse.

The purpose of this study was to examine the links between childhood sexual abuse, shame, and the difficulty in recovery experienced by some alcoholic women. The role of shame in the recovery process of alcoholic women is important to understand in order to expand knowledge, improve treatment, and reduce human suffering.

\section{Research Background and Hypotheses}

Research suggests that an important area for study regarding alcoholic women is the experience of childhood sexual abuse. Studies have shown a high incidence of childhood sexual abuse among alcoholic women (Covington, 1982; Covington \& Kohen, 1984; Hurley, 1991; Kovach, 1986; Miller \& Downs, 1993; Miller, et al., 1987 Wilsnack, 1984; Wilsnack, Vogeltanz, Klassen, \& Harris, 1997; Wilsnack \& Wilsnack, 1991). Research has suggested that the experience of childhood sexual abuse is predictive of later development of alcoholism (Miller et al., 1987; Root, 1989). The sexual abuse experienced by alcoholic women in childhood has been found to be more severe and to have occurred more frequently over a longer period of time than the sexual abuse experienced by non-alcoholic women (Covington \& Kohen, 1984; Miller \& Downs, 1993; Miller et al., 1987).

Researchers have suggested a number of differences between alcoholic women who have experienced childhood sexual abuse and those who have not (Goodale $\&$ Stoner, 1994; Hall, 1996; Kovach, 1986; Miller et al., 1987; Root, 1989; Skorina \& Kovach, 1986). Some indicate that for survivors of childhood sexual abuse, alcoholism has developed secondary to Post Traumatic Stress Disorder (PTSD) (Kovach, 1986, Skorina \& Kovach, 1986). Others posit that for survivors of childhood sexual abuse, alcoholism occurs concomitantly with other disorders such as depression or dissociative disorder (Goodale \& Stoner, 1994; Hall, 1996). Alcoholic women with a history of sexual abuse may also have higher rates of relapse and more difficulty in relationships and managing their emotions well into recovery (Hall, 1996; Kovach, 1986). In any case, it appears that alcoholic women who have experienced childhood sexual abuse have a more difficult recovery than women who have not experienced childhood sexual abuse.

Unfortunately, very little research exists on the differences between alcoholic 
women who have experienced childhood sexual abuse and those who have not. The studies that have been conducted have used small numbers of participants and lacked comparison groups; therefore the results are highly speculative. The findings suggest that these two groups of women differ in their recovery process (Goodale \& Stoner, 1994; Hall, 1996; Kovach, 1986; Skorina \& Kovach, 1986). Hall (1996) and Skorina and Kovach (1986) identified shame as a contributor to problems that alcoholic women who were survivors of childhood sexual abuse experienced in recovery. To my knowledge no study has been conducted that specifically examines the relationships between childhood sexual abuse, internalized shame, and difficulty experienced in recovery.

This study was designed to examine the impact of childhood sexual abuse on shame and recovery for alcoholic women. Childhood sexual abuse was broadly defined to include both contact and non-contact (exposure, lewd remarks, etc.) sexual acts perpetrated upon a child up to 18 years of age by an adult or older child. Shame was conceptualized as internalized or trait shame.

Thus, shame is considered to be a primary affect inherent to humans that has self-regulatory purposes. However, when shame is triggered chronically or inappropriately, it is internalized and becomes connected to the individual's identity and sense of self (Cook, 1996; Kaufman, 1996). It was hypothesized that the alcoholic women who experienced childhood sexual abuse would have higher levels of internalized shame and, therefore would have more difficulty in recovery than the women who did not experience childhood sexual abuse. Background, mental health, and addiction variables were examined for their effects on the outcome variables.

The hypotheses examined were:

$\mathrm{H} 1$ : Of the women recovering from alcoholism in $\mathrm{AA}$, those who report having experienced childhood sexual abuse will have more severe shame.

Hla For those experiencing childhood sexual abuse, the more severe the abuse experience, the more severe their shame experience will be.

$\mathrm{H} 2$ : Of the women recovering from alcoholism in AA, those who report having experienced childhood sexual abuse will report more difficulty in recovery.

H2a: For those experiencing childhood sexual abuse, the more severe the experience of childhood sexual abuse, the more difficulty in recovery will be experienced.

H3: Those with more severe shame will have more difficulty in recovery. 


\section{Methodology}

This correlation study examined the experiences of 53 alcoholic women in recovery in Alcoholics Anonymous (AA) in Pittsburgh, Pennsylvania. The sample was obtained through a combination of direct sampling by the researcher and snowball sampling. A letter describing the study, requirements for participation, and compensation was distributed to female AA members as they left AA meetings. Also, women who participated in the study and AA members known to the researcher were asked to distribute the letter to other women AA members. Retrospective data regarding the existence and severity of a history of childhood sexual abuse and a history of alcoholism/addiction were obtained as well as data on the participants' current experience of shame, social adjustment status, and background variables. The data were gathered in a one to two hour session using a semi-structured interview and two self-report scales.

The Internalized Shame Scale (Cook, 1994) was used to measure shame and the Social Adjustment Scale - SR (Weissman \& Bothwell, 1976) was used to measure social adjustment in recovery. The childhood sexual abuse portion of the Childhood Trauma Interview (Fink, Bernstein, Handlesman, Foot, \& Lovejoy, 1995) was used to obtain data on childhood sexual abuse. Respondents reported the number of times that they had relapsed and were placed in a category of either yes relapse or no relapse. Participants were given a $\$ 20.00$ gift certificate as compensation for their participation in the study.

Members who reported a history of childhood sexual abuse $(n=36)$ were compared to members who did not report a history of childhood sexual abuse $(\mathrm{n}=17)$ on their levels of internalized shame, relapse, and social adjustment in recovery. The impact of the severity of childhood sexual abuse on the levels of internalized shame, relapse, and social adjustment were examined as well. The bivariate relationships between the variables were examined using t-tests, Chi square analyses, and Pearson correlations.

Results

The results indicated that a strong link between internalized shame and difficulty in recovery in terms of both relapse, $\underline{\mathrm{t}}(51)=2.4, \mathfrak{p}=<.05$, and impaired social adjustment $(r=.49, \underline{p}=<.001)$ did exist. The findings suggested that the level of internalized shame in this sample $(\underline{M}=48.77, \underline{S D}=15.86)$ approximated the problematic level of 50 as identified by Cook (1994). Internalized shame appears to be an important treatment issue for alcoholic women.

The expectation that alcoholic women who were recovering in $\mathrm{AA}$ and reported a history of childhood sexual abuse would have higher levels of internalized 
shame and more difficulty in recovery than those who did not experience childhood sexual abuse was not supported. The expectation that the recovering women with a history of more severe childhood sexual abuse experiences would have higher levels of internalized shame and more difficulty in recovery than those with a less severe history of childhood sexual abuse was not supported either.

The lack of significant differences between these groups may have been due to the small sample size and how the sample was distributed in the subgroup analyses. Similarly, the lack of significant findings on the impact of the severity of sexual abuse on internalized shame and difficulty in recovery analyses were likely due to diminished statistical power as well. Finally, variations in the amount of recovery time may have had an impact on shame scores $(r=-.32, p<.05)$.

\section{Utility for Social Work Practice}

Although the main hypothesis was not supported, the data provide useful information that enhances our understanding of alcoholism in women. The finding that shame does have significant impact on difficulty in recovery suggests that social workers need to pay particular attention to the internalized shame that an alcoholic woman feels. If an alcoholic woman seeks help, for any reason, and is responded to in a way that is confrontational or blaming, she may experience more shame. Compounding her shame will only compound the problem and reduce the chances that she will return for help. Many treatment approaches offer models for approaching shame, such as Feminist therapy, Cognitive therapy, and Gestalt therapy that are congruent with social work values. Social work practitioners need to develop and utilize intervention strategies that are sensitive to the profound shame that their clients may be experiencing.

Social workers are in the unique position of being able to identify women's problems and needs in a variety of settings. Historically, the social work profession has not embraced the addiction problem. Schools of social work have not required addiction training in their curricula; thus graduates are ill prepared to identify and address addiction problems in clients. There is a trend however, in some schools of social work, to integrate a course or a concentration related to alcohol and drugs into their curricula. Such schools recognize the importance of training all students on the pervasive problem of alcoholism and its appropriate identification and treatment. NASW recently established a division on alcohol, tobacco, and other drugs which supports social workers working in the addiction field. In service to our mission, the social work profession should continue to take steps to address the problem of alcoholism and other drug addictions in society. 


\section{References}

Abbott, A. A. (1995). Substance abuse and the feminist perspective. In N. Van Den Bergh (Ed.), Feminist practice in the 21 st century. Washington, DC: NASW Press.

Briere, J., \& Runtz, M. (1993). Childhood sexual abuse: Long-term sequelae and implications for psychological assessment. Journal of Interpersonal Violence, 8(3), 312-330.

Cook, D. R. (1994). Internalized Shame Scale: Professional manual. Menomonie, WI: Channel Press.

Cook, D. R. (1996). Empirical studies of shame and guilt: The Internalized Shame Scale. In D. L. Nathanson (Ed.), Knowing feeling affect, script, and psychotherapy (pp. 132-165). New York: W.W. Norton \& Company.

Covington, S., \& Kohen, J. (1984). Women, alcohol, and sexuality. In B. Stimmel (Ed.), Cultural and sociological aspects of alcoholism and substance abuse (pp. 41-56). New York: Haworth Press.

Covington, S. S. (1982). Sexual experience, dysfunction, and abuse: A descriptive study of alcoholic and nonalcoholic women. Unpublished Dissertation, The Union Graduate School.

Feiring, C., Taska, L., \& Lewis, M. (1996). A process model for understanding adaptation to sexual abuse: The role of shame in defining stigmatization. Child Abuse and Neglect, 20(8), 767-782.

Fink, L. A., Bernstein, D., Handlesman, L., Foote, J., \& Lovejoy, M. (1995). Initial reliability and validity of the childhood trauma interview: A new multidimensional measure of childhood interpersonal trauma. American Journal of Psychiatry, 152(9), 1329-1335.

Gomberg, E. S. L. (1988). Shame and guilt issues among women alcoholics. Alcoholism Treatment Ouarterly, 4(2), 139-155.

Goodale, T. S., \& Stoner, S. B. (1994). Sexual abuse as a correlate of women's alcohol abuse. Psychological Reports, 75, 1496-1498.

Hall, J. M. (1996). Pervasive effects of childhood sexual abuse in lesbians' recovery from alcohol problems. Substance Use and Misuse, 31 (2), 225-239.

Hurley, D., L. (1991). Women, alcohol and incest: An analytical review. Journal of Studies on Alcohol, 52(3), 253-268.

Kaufman, G. (1996). The psychology of shame. (2nd ed.). New York: Springer Publishing Company.

Kovach, J., A. (1986). Incest as a treatment issue for alcoholic women. Alcoholism Treatment Quarterly, 3(1), 1-15.

Miller, B. A., \& Downs, W. R. (1993). The impact of family violence on the use of alcohol by women. Alcohol Health and Research World, 17(2), 137-143.

Miller, B. A., Downs, W. R., Gondoli, D., \& Keil, A. (1987). The role of childhood sexual abuse in the development of alcoholism in women. Violence and Victims, 2(3), 157-172. 
Nathanson, D. L. (1989). Understanding what is hidden: Shame in sexual abuse. The Psychiatric Clinics of North America, 12(2), 381-388.

National Institute of Alcohol Abuse and Alcoholism. (1993). 8th special report to the U.S. congress on alcohol and health (Pre-print copy). Alexandria: EEI.

Klee, L., Schmidt, C., \& Ames, G. (1991). Indicators of women's alcohol problems: What women themselves report. The International Journal of the Addictions, 26(8), 879-895.

Playter, J. (1990). The effect of childhood sexual abuse on internalized shame in adult women in treatment for chemical dependency. Unpublished Masters Thesis, University of Wisconsin-Stout, Menomonie.

Ramsey, E. (1988). From guilt through shame to AA: A self-reconciliation process. Alcoholism Treatment Quarterly, 4(2), 87-106.

Root, M. P. (1989). Treatment failures: The role of sexual victimization in women's addictive behavior. American Journal of Orthopsychiatry, 59(4), 542-549.

Rosenhow, D., J., Corbett, R., \& Devine, D. (1988). Molested as children: A hidden contribution to substance abuse. Journal of Substance Abuse Treatment, 5(1), $13-18$

Skorina, J. K., \& Kovach, J. A. (1986). Treatment techniques for incestrelated issues in alcoholic women. Alcoholism Treatment Quarterly, 3(1).

Weissman, M. M., \& Bothwell, S. (1976). Assessment of social adjustment by patient self report. Archives of General Psychiatry, 33, 1111-1115.

Wilke, D. (1994). Women and alcoholism: How a male-as-norm bias affects research, assessment, and treatment. Health and Social Work, 19(1), 30-35.

Wilsnack, S. C. (1984). Drinking sexuality and sexual dysfunction in women. In S. C. Wilsnack \& L. J. Beckman (Eds.), Alcohol problems in women: Antecedents, consequences and intervention (pp. 189-227). New York: Guilford Press.

Wilsnack, S. C., \& Wilsnack, R. W. (1991). Epidemiology of women's drinking. Journal of Substance Abuse, 3, 133-157.

Wilsnack, S. C., Vogeltanz, N. D., Klassen, A., \& Harris, T. R. (1997). Childhood sexual abuse and women's substance abuse: National survey findings Journal of Studies on Alcohol, 58(3), 264-271. 